\title{
Reflection of the Type of Medical Curriculum on Its Anatomy Content: Trial to Improve the Anatomy Learning Outcomes
}

\author{
Ahmed M. S. Hegazy ${ }^{1,2}$, Liaqat Minhas ${ }^{2}$ \\ ${ }^{1}$ Anatomy Department, Benha Faculty of Medicine, Benha University, Benha City, Egypt \\ ${ }^{2}$ Anatomy Department, Faculty of Medicine, Northern Border University (NBU), Arar City, Saudi Arabia \\ Email address: \\ ahmed0562301954@yahoo.com (A. M. S. Hegazy)
}

\section{To cite this article:}

Ahmed M. S. Hegazy, Liaqat Minhas. Reflection of the Type of Medical Curriculum on Its Anatomy Content: Trial to Improve the Anatomy Learning Outcomes. International Journal of Clinical and Developmental Anatomy. Vol. 1, No. 3, 2015, pp. 52-63.

doi: $10.11648 /$ j.ijcda.20150103.11

\begin{abstract}
Doctors without anatomy are like a blind that deceives the road in the desert. Traditionalists perceive a decline in Anatomy knowledge and attribute it to the modern methods of teaching and learning. Reformers point to evidence that modern approaches offer equivalent results in assessment when compared to traditional courses. It seems that there are three aspects that need to be resolved: when, how much, and how to teach anatomy. In this study we reviewed more than 80 articles to conclude some guidelines which can help in improving anatomy learning outcomes in different medical curricula. Conclusions: We concluded that the challenge should not be to determine supremacy of one methodology over another but to maximize the learning benefit available from the different methods. In any model of medical curricula, a professional team of medical anatomists have to share in all the steps of curriculum building, the assessment tools and the final evaluation till the approval of the curriculum to: 1- Ensure that all the basic anatomical objectives are chronologically arranged and sufficiently covered in a suitable time and methodology without inflation of the curriculum by more sophisticated details which taught only for the postgraduate students and medical anatomists. 2- Prevent any restriction of important basic knowledge which will not be covered later on and will affect the physician medical practice. 3- Ensure that all the basic anatomical objectives are demonstrated with their clinical application without the sophisticated details of the clinical points which will be taught in details in the clinical years.
\end{abstract}

Keywords: Anatomy, Teaching, Medical Curriculum, Medical Education, Methodology

\section{Introduction}

The term curriculum has been defined by many authors as: A plan for action or a written document that includes strategies for achieving desired goals or ends [1].

A document which usually contains a statement of aims and specific objectives. It indicates some selection and organization of content; it either implies or manifests certain patterns of learning and teaching, finally it includes a program of evaluation of the outcomes [2].

Course of learning activities set out for the learner to perform to make him achieve certain goals prescribed by the educational system. The curriculum generally includes all subjects and activities over which the school has responsibility. It also defines the limits within which certain types of learning are to take place. It denotes those experiences and activities which are devised by the school or other institutions of learning for the purpose of changing a learner's behavior, acquiring or reinforcing certain skills and preparing him to fit properly into his society [3].

Anything and everything that teaches a lesson, planned or otherwise. Humans are born learning, thus the learned curriculum actually encompasses a combination of all of the following, the hidden, null, written, political and societal etc.. Since students learn all the time through exposure and modeled behaviors, this means that they learn important social and emotional lessons from everyone who inhabits a school, from the janitorial staff, the secretary, the cafeteria workers, their peers, as well as from the deportment, conduct and attitudes expressed and modeled by their teachers. Many educators are unaware of the strong lessons imparted to youth by these everyday contacts [4]. 
In contrast to the growth of curricular structure, the passage of the idea - the concept of what the realm of the curriculum might be-became highly diffused, and two consequences persist. First, the curriculum as a concept, as a discrete idea, is almost without boundaries. It can mean anything from the "bundle" of programs an institution offers to the individual experience of a particular student. Second, systematic description, that is, an orderly, technical terminology that enhances insights on practice and links ideas to application, has not developed. "What we appear to lack, is a general vocabulary or framework for understanding the nature of knowledge and skills across university disciplines [5]. Often faculty at work on the curriculum must invent their own labels to describe what they do.

The idea of a curriculum has been differentiated across a wide range of meanings. One basic view is that curriculum is "what is taught" [6]. A narrow view holds that curriculum is "the bodies of courses that present knowledge, principles, values, and skills that are the intended consequences of formal education" [7]. The broad view holds that "the curriculum ... will have to be conceived as the name for the total active life of each person in college" [8]. Even the set of choices from which the curriculum can be defined is broad.

Some see a split in the definition:

It is important at the outset to distinguish clearly between two meanings of the term "curriculum." The word [can] connote either formal structural arrangements or the substance of what is being taught. (To be sure, the relations between form and substance, here as always, are complex.) [9].

Others find evidence of six uses:

1. A college's - or program's - mission, purpose, or collective expression of what is important for students to learn

2. A set of experiences that some authorities believe all students should have

3. The set of courses offered to students

4. The set of courses students actually elect from those available

5. The content of a specific discipline

6. The time and credit frame in which the college provides education [10].

The history of the curriculum is one in which theories are never realized in the manner they are intended. There are always unintended, unanticipated, and unwilled consequences as theories are put into social action [11].

If "design" holds advantages over "theory" as the way to invest the curriculum with practical effectiveness, how can it be applied? Any elaboration of the idea should provide boundaries and reasonable specificity; but, most important, the refinement of definitions should not be so detailed that it hampers the judgment of those who have to work with it [12]

The implications of the preceding subsection can be woven into a comprehensive definition: The curriculum is an intentional design for learning negotiated by faculty in light of their specialized knowledge and in the context of social expectations and students' needs. That definition might be a bit stodgy, but it does sharpen the point that a curriculum is an artifact produced by a particular faculty for students at a particular institution. The essential qualities are all there: faculty responsibility, specialized knowledge, intended outcomes, negotiated relationships, and a learning plan for students [12].

The term curriculum is reserved for an institution's entire educational program. It is the locus of corporate responsibility for learning that engages faculty, trustees, administration, and students. The curriculum encompasses all the sectors of the institution involved with the process of teaching and learning [12].

\section{Practice of Medicine}

Practice of medicine becomes increasingly complex with each passing year. Technological advances and research findings leading to improved methods of disease prevention, diagnosis and treatment produce a constantly changing definition of the competence, a medical students must acquire. Various models of medical curriculum described by McGaghie et.al., (1978) [13] are:

I. Subject - centered curriculum

II. Integrated curriculum

III. Competency - based curriculum

These models emphasize the process of curriculum construction rather than its content.

\section{Medical Curriculum}

Medical curriculum of any country is designed in accordance with their national health need. It highlights the kind of physician expected to graduate from its medical colleges and universities, outcomes and competencies, and is based on best evidence in medical education. An undergraduate medical curriculum usually has about twenty disciplines. Anatomy is one of the most important components of the curriculum which is usually taught in first years.

In recent decades wide-ranging changes have occurred in medical school curricula. Time spent studying gross anatomy has declined amidst controversy as to how, what, and when teaching is best delivered. This reduced emphasis has led to concerns amongst clinicians that a new generation of doctors are leaving medical school with insufficient anatomical knowledge. Previous studies have established that medical students value their anatomy teaching during medical school. None have sought to establish views on the sufficiency of this teaching [14].

\subsection{The Current Anatomy Situation}

Doctors without anatomy are like moles.They work in the dark and the work of their hands are mounds (Tiedemann: Heidelberg, 1781-1861) [15].

Fitzgerald et.al., (2008) [14] have investigated the opinions of newly qualified doctors at a UK medical school and related these opinions to career intentions and academic 
performance in the setting of a traditional dissection and prosection-based course. Overall nearly half of respondents believe they received insufficient anatomy teaching. A substantial proportion called for the integration of anatomy teaching throughout the medical school course. Trainees intent on pursuing a surgical career were more likely to believe anatomy teaching was insufficient than those pursuing a nonsurgical career; however, overall there was no statistical difference in relation to the mean for any individual career group. The study adds to the current debates in anatomical sciences education, indicating that overall, regardless of career intentions, new doctors perceive the need for greater emphasis on anatomical teaching.

It is undisputed that anatomy still has a role in the process of training doctors and supporting modern medical practice. All medical schools, new and old, still maintain anatomy as a core subject in their curricula. Over the last 20-30 years, all anatomy curricula have been reduced to lessen the factual burden on students and make time for teaching other skills. This reduction will have an effect on the training of future surgeons (and some other specialists) but perhaps it is the specialists', or anatomists', responsibility to provide the necessary training at a later, more appropriate, time in training. Unfortunately, the evidence suggests that the curricula and teaching have diminished too much, to an extent where safety and clinical practice might be compromised. If this is the case, it can be attributed to reduction in resources and the resultant effects on teaching methodology in the modern medical curriculum. Anatomy has traditionally been delivered at the beginning of medical education to provide a basis for clinical training and practice. A dogmatic support amongst traditionalists for detailed anatomy courses may have been detrimental to the evolution of anatomy as a subject. Reformers regard these teaching methods to be 'old-fashioned' and incompatible with modern learning practices possibly without appreciating the many benefits of the traditional approaches [15].

\subsection{Anatomy Crisis}

Anatomical knowledge supports examination of a patient, the formation of a diagnosis and communication of these findings to the patient and other medical professionals. It provides a platform of knowledge suitable to all medical careers. Anatomy has been a cornerstone of medical education for hundreds of years. Many argue that it has survived the most demanding pedagogic test - time. However, in recent years, human anatomy has been slowly squeezed from the medical curriculum [15].

Anatomy, the unshakable foundation of medical teaching for hundreds of years, has in the past decade become a surprisingly controversial area of medical education [14]. Disagreements surround teaching styles, content, and the time dedicated to gross anatomical courses within the greater medical school curriculum [16]. Many anatomists and clinicians judge anatomy to be in a state of crisis, with traditional teaching marginalized $[17,18]$. Others dubbed with a more "modernist" approach are embracing new, often unproven, methods that have seen the end of dissection and even cadaveric-based teaching in some schools [19]. Criticism in recent decades regarding an overcrowded medical school curriculum delivered via didactic, passive techniques has resulted in revised medical courses throughout the world [20]. These now cover a spectrum from problem-based to systems-based, delivered via lectures, clinical skills, and small-group classes [21-23]. Within this, anatomy teaching in the UK utilizes a range of formats including dissection, prosection, information technology, living anatomy, and models [24]. Yet there is scant published evidence on outcomes underlying many of these varied teaching styles and techniques. Much simply relies on perceptions of the learning experience and course feedback from students [25]. Frequently these support the particular style of teaching employed by the author rather than attempting a critical appraisal [14].

Recently, much attention has focused on the perceived lack of anatomical knowledge of Australian medical graduates, both in the popular press [26] and academic literature [27,28]. A sustained decline in the number of hours dedicated to teaching anatomy from the mid-1990s has been attributed to the introduction of integrated, problem-based curricula [15], the redesign of medical curricula to accommodate a vast expansion in basic science knowledge [29], as well as the rise of time-poor, four-year graduate programs [30].

Anatomy is obviously essential for surgeons but also has value for anyone who performs an invasive procedure on a patient; carries out emergency procedures; examines radiological imaging; performs a physical examination of a patient; refers a patient to another doctor; or explains a procedure to a patient. These tasks are common to all branches of medicine. Arguably, all of these tasks can be done without underlying knowledge of anatomy by following protocols and guidelines and using pattern recognition. This may be a cost-effective approach, and can rapidly provide service provision to a health service, but learning without understanding cannot be regarded as a deep approach to learning [31].

In the UK, the General Medical Council (GMC) offers no guidance on what is a minimum knowledge requirement for any medical subject but instead leaves it to the medical schools to determine their own curricula and own methods of assessment [15].

\subsection{Integration of Anatomy Vertically into Medical Education}

Historically, anatomy has been taught predominantly in the first undergraduate year. Although anatomical knowledge is assessed again in many specialist professional examinations, there is very limited exposure to anatomy teaching in later training. This is educationally unsound, as an excessive amount of seemingly irrelevant material in a curriculum encourages superficial learning [32]. Given only one opportunity to teach anatomy, it is difficult to calculate the quantity of anatomical detail that should be included: should 
a course be preparing future generalists or specialists? A solution would be to integrate anatomy vertically into medical education so that students are exposed to anatomy teaching throughout undergraduate (preclinical and clinical), postgraduate and later professional training. This would provide relevant anatomy at an appropriate level of detail to the stage in training or career development. Tailoring theoretical learning to a particular specialty would reduce the amount of unnecessary theory learnt [15].

It has been argued that in the past students were overloaded with facts, but were not adequately prepared for effective communication with patients. This has been addressed in many medical schools by the introduction of problem-based, self-directed and patient-centered learning which at the same time shifts learning away from factual recall towards a broader range of activities including clinical skills. However, common sense dictates that there must be a necessary minimum of factual Knowledge in basic medical disciplines to allow a medical practitioner to examine their patients effectively and to undertake simple procedures safely It follows that this core knowledge should be the same, whatever teaching approaches are adopted within a curriculum [33].

The way anatomy teaching fits recent changes deserves particular attention. There are two directly competing realities concerning the pre-clinical years: fast expansion of knowledge in basic medical disciplines, requiring more teaching time, and a strong tendency to reduce teaching time, particularly in problem-based curricula [35]. Within anatomy itself, there is a "competition for space and time" between recently introduced but quickly accepted perspectives (eg, surface and imaging anatomy, applied and clinical anatomy, anatomical variations) that are becoming an integral part of the anatomy teaching.

\subsection{Decline in Undergraduate Knowledge of Anatomy}

For nearly 30 years, there has been discussion of the decline in undergraduate knowledge of anatomy amongst the surgical community $[17,24,36,37,38]$. These studies report reductions in allocated time, teaching staff and dissection in most anatomy courses. It is very difficult to assess objectively whether this reduction in anatomy teaching has been excessive. However, the few studies that have been conducted suggest that the knowledge of the qualifying doctor is now below an acceptable level $[35,39,40]$.

Anatomy has an established value in medical education and is supported by students, clinicians, anatomists and the general public. Is the decline of anatomy a result of reductions in time and resources allocated to anatomy teaching or is it a result of the changes in teaching methodology?

Gross anatomy is one of the fundamental topics in medical education. By learning gross anatomy, medical students get a first impression about the structure of the normal human body, which is the basis for understanding pathologic and clinical problems. Dissection courses still play an important role in learning gross anatomy, in addition to lectures and seminars. Also, training courses for imaging (x-ray, magnetic resonance imaging, computed tomography, sonography) as well as computer-assisted learning environments are part of a student's gross anatomy curriculum. However, the anatomical knowledge acquired during medical school is usually not sufficient for postgraduate training as a physician, in particular, as a surgeon or radiologist [41].

Experience in maintaining excellence in teaching human anatomy is important in mitigating the decline in undergraduate knowledge in the subject [42]. The decline has been attributed to reduction in teaching time allocated in teaching the subject, inadequate teaching staff and diminishing emphasis on dissection $[15,17,24,35,43]$. This undermines the importance of human anatomy as a pillar in medical education [38,44] making them unsafe. Consequently medical professional bodies, legal fraternity and patients themselves are reappraising the need for greater indepth knowledge of anatomy among doctors $[15,45]$. In response, there is resurgence in the value and emphasis of human anatomy [46]. There is however, wide diversity in modes of teaching in human anatomy departments with varying emphasis on each of the methods individually or in combination [47-51]. This has resulted in wide variation in curriculum designs, duration, staffing numbers and composition [24]. In Africa, although $90 \%$ of the medical schools have retained dissection [52,53] challenges of reduced time, staff shortages, declining financial allocations and rising student numbers are pushing for change [54].

Anatomy remains one of the core courses of medical school, but the time devoted to it is decreasing. To accommodate the explosion of medical knowledge, educators search to streamline the curriculum. Because it is timeconsuming, dissection comes under increased scrutiny. Even in the face of these pressures to reduce course hours, Rizzolo, [55] proposed broadening, not reducing, the responsibilities of the anatomy instructor. Anatomy instructors can play a crucial role in helping medical schools meet the critical need to cultivate humanistic values, especially in the arena of endof-life care. Anatomy can--and should--play an important role in a curriculum-wide effort to address this issue. Just as dissection remains an essential technique to teach threedimensional concepts, the cadaver dissection lab is an ideal place to introduce concepts of humanistic care. The lab evokes the students' memories, speculations, and fears about serious illness in themselves, their families, and loved ones. Some programs address these reactions with supplemental activities, such as journaling, essay writing, and small group discussion. Valuable as these activities may be, anatomy instructors can achieve more by recognizing their role as a mentor, who can integrate humanistic values into traditional course objectives in a way that adds little time to the curriculum. The attitude of the instructor in ministering to the students' needs as they undertake the emotionally charged task of dissection can provide a model for how the students will respond, in turn, to the hopes and fears of their patientsand to their own reactions to dying. This approach will allow students to implement and practice humanistic values 
immediately, laying a foundation for their clinical training [55].

One point universally agreed is the reduction in time allocated to anatomy teaching across North America, the UK, Europe, Asia, and Australasia [24,25,56-59]. Time spent studying anatomy is worthless without quality teaching resources underpinning it, yet many have used this reduction as an indicator of declining standards [14]. These concerns have been voiced increasingly loudly, not just by anatomists but also clinicians from a range of specialities. Such changes, both in curriculum and teaching styles, are said to have led to insufficient anatomical knowledge amongst students and junior doctors $[35,60,61]$. Surveys of clinical staff have shown that a majority perceive current anatomical education to be inadequate in both the UK (Waterston and Stewart, 2005) [39] and North America (Cottam, 1999)[56].

Not only there is an educational and professional standpoints but also litigious factors supporting doctors' need for anatomical knowledge. Between 1995 and 2000, there was a 7 -fold increase in claims associated with anatomical errors submitted to the Medical Defence Union and, recently, $32 \%$ of claims made to the Medical Defence Union in general and vascular surgery were reported to be for 'damage to underlying structures' [62].

Recent years have seen a dramatic increase in the published medical literature addressing the educational aspects of modern anatomy teaching. Despite the wideranging changes to medical school curricula described earlier, the importance of anatomy teaching within these courses is not in doubt. However, considerable controversy remains as to the shape and form this should take [14].

\subsection{How to Teach Anatomy}

Much debate has arisen about how to teach anatomy. This polarises into those that favour dissection of human cadavers and those that support newer teaching modalities (e.g. selfdirected learning, problem-based learning [PBL], and computer-assisted learning [CAL]). These standpoints tend to be supported by either the traditionalists (predominantly surgeons and anatomists) or the modernists (predominantly educationalists), respectively. This, however, does not address the fundamental reasons why anatomy is in decline [15].

Anatomy as a subject has suffered as a result of its failure to evolve and adapt quickly enough. Under old-style medical training, students were expected to learn detail with little understanding of relevance. Learning anatomy became a rite of passage rather than an educationally valid process and clearly required reform. Anatomy has suffered as a subject because it is regarded as banausic, archaic, didactic, traditional, overly factual and unable to adapt to modern educational methods - an obvious target for those looking to reduce curriculum content and modernise the learning experience [15].

Anatomy is also subject to many extrinsic pressures. Maintaining a dissecting room in accordance with national and European laws is very costly and changes in anatomy departments and surgical training have reduced the numbers of medically qualified anatomy teachers [63]. This is within the context of an increase in numbers of medical students which puts more pressure on an overstretched system.

The combined problems of a banausic image and an unsupportive academic infrastructure may explain the decline of anatomy as a subject more than the teaching methodology changes in the last 15-20 years.

In an analysis of teaching and learning, it is necessary to examine the curriculum, the mode of teaching, the quality of how this is delivered and the infrastructure within which it is delivered [15].

Schmidt et.al., (1987) [64] have reviewed 15 studies that compare various educational outcomes of problem-based, community-oriented medical curricula with those of conventional programs. The data suggest that problem-based curricula provide a student-centered learning environment and encourage an inquisitive style of learning in their students as opposed to the rote memorization and short-term learning strategies induced by conventional medical education. In addition, community-oriented schools appear to influence the career preferences of their students. The few data available show that significantly larger proportions of graduates from these schools seek careers in primary care. Some of the studies reviewed suggest that students in conventional programs perform somewhat better on traditional measures of academic achievement than do students in problem-based curricula. However, these differences, if any, tend to be very small. Data with respect to performance on instruments measuring clinical competence are inconclusive. Finally, the authors discuss the difficulties involved in carrying out comparative research at the curriculum level [64].

\subsection{Anatomy Which Independent Medical Practitioner Should Know}

A minimum working knowledge should be that which allows an independent practitioner to practice safely, and to communicate with other medical professionals and patients effectively [15].

Recently, some of the country's leading anatomists have put together some guidelines on an anatomy curriculum which they feel any independent medical practitioner should know [65]. This consensus should be welcomed, as it allows a benchmark to be set for medical schools. It is hoped that it will allow better comparisons of teaching methodology and permit meaningful assessment of both medical students and teaching establishments to take place.

The professional colleges have also produced syllabi outlining the level of anatomical knowledge that they expect from their members when examined. Specialist trainees will rightly require more detailed knowledge of anatomy than the guidelines of Dyball et.al., (2003) [65], but at a later stage in their training. Consequently it may be that these specialist levels of knowledge can only be met by vertically integrating anatomy into medical training [15].

Heylings, (2002) [24] has reviewed the impact of 
Tomorrow's Doctors on anatomical teaching in the UK and Ireland. To establish in particular whether a consensus has emerged on: (a) the duration and format of teaching, and (b) the impact on staffing and on the four main anatomical disciplines of gross anatomy, histology, embryology and neuroanatomy. A postal survey of 28 anatomy departments was carried out. This yielded a response rate of $75 \%$. Twelve departments used systems-based curricula, five used problem-based curricula, and four used a traditional regional format. There were variable levels of integration between the anatomical disciplines and subjects outside anatomy. Dissection taught over the first 2 years was retained in $76 \%$ of the courses, frequently supplemented with demonstrations, with an average of 2 hours of practical work for every hour of lecture. Staff/student ratios varied with the type of curriculum: dissection room teaching and problem-based curricula were associated with higher numbers of either full or part-time clinically qualified teachers. Teaching was supported by a high proportion of part-time clinically qualified staff, giving an overall average staff/student ratio of 19.8 in a dissection class. He concluded that there was considerable variation in duration and staffing of anatomy teaching, according to the type of curriculum. This suggests there may well be substantial variation in the level, content and depth of anatomical curricula across the country, and that this should be quantified [24].

In the UK, the General Medical Council (GMC) offers no guidance on what is a minimum knowledge requirement for any medical subject but instead leaves it to the medical schools to determine their own curricula and own methods of assessment. Traditionalists perceive a decline in knowledge and attribute it to the modern methods of teaching and learning. Reformers point to evidence that modern approaches offer equivalent results in assessment when compared to traditional courses. It seems that there are three aspects that need to be resolved: when, how much, and how to teach anatomy [15].

Teaching anatomy to both undergraduate medical students and medical graduates is in the midst of a downward spiral. The traditional anatomy education based on topographical structural anatomy taught by didactic lectures and complete dissection of the body with personal tuition, has been replaced by a multiple range of special study modules, problem-based workshops, computers, plastic models and many other teaching tools. In some centers, dissected cadaver-based anatomy is no longer taught. Changing the undergraduate medical curriculum in the UK has taken place without any research into the key aspects of knowledge necessary or comparing methods of teaching. There is no agreement on a common national core curriculum and as a result, numerous new curricula have been introduced. No external audit or validation is carried out, so medical schools have been free to teach and assess their own work themselves. There is a great divergence in medical schools across the UK and Ireland in teaching medicine in general and anatomy in particular. Published data on the impact of these changes is scant. The reduction in undergraduate teaching and knowledge of anatomy has caused great concern, not only for undergraduates but also to postgraduate students, especially in surgery. This, together with a change in basic surgical training, a marked reduction in demonstrator posts and a change in examination standards, has set up a system that is allowing young men and women with a poor knowledge of anatomy to become surgeons. There should be a full public debate at every level; the Royal Colleges, specialist associations, the Universities, Government, both health and education. This debate should highlight areas of concern, explore in depth and define a minimal core curriculum for anatomy. Teaching must be enhanced with a critical look at both teachers and methods. The dominance of research must be reassessed to establish an equitable cohabitation with teaching. The place of basic science, especially anatomy in basic surgical teaching, must be examined. A thorough knowledge of anatomy should be required in the new MRCS-UK. This should be mandatory as a preliminary to higher surgical training. The teaching of anatomy in surgical specialities must be improved. Does the dissecting room still have a place in educating our under- and postgraduate students? Yes--a sound knowledge of anatomy is essential if the medical practitioner is going to accurately define and successfully treat the problem presented by the patient. The dissected cadaver remains the most powerful means of presenting and learning anatomy as a dynamic basis for solving problems. The cadaver must not be dismissed as obsolete. Dissection has survived the most rigorous test of pedagological fitness--the test of time. The student--cadaver-patient encounter is paramount in medical education [17].

\subsection{What is the Best Way to Teach Gross Anatomy}

Traditionally, learning anatomy has been dissection-based. Dissection has become synonymous with traditional courses and has come to be regarded as the antithesis of problembased learning (PBL). However, dissection would appear to be ideally suited to self-directed learning: students exploring a subject for themselves at their own pace, in a practical way and according to their own personal interests. Surgeons advocate experience with dissection not only to help to learn anatomical detail but to familiarise students with the variation in anatomy and to obtain an appreciation of fully exposed structures that cannot be seen through the window of an operation but that might be damaged inadvertently. Perhaps most significantly, students have a high regard for dissection as a learning resource in the anatomy course [66] and many other learning outcomes have been identified by students [67]. Dissection allows haptic (based on a sense of touch) appreciation of 3-D anatomy unlike any other teaching facility. However, dissection as a learning modality has been marginalised from medical curricula to the despair of some academics [68-70].

In the last 15-20 years, some universities have embraced other learning modalities. One of the most popular alternatives is problem-based learning (PBL) developed at McMaster University in the late 1970s by Barrows and Tamblyn [71]. They developed a medical school curriculum based solely on small group, student-centred learning. The 
rationale behind this was first that problem-based rather than memory-based learning created a more usable body of knowledge and second that the medical skills that were most important for treating patients were problem-solving skills rather than memorisation. Key to its success was that, by working in small groups, students identified deficiencies in their knowledge and skills and resolved these themselves.

The original advantages identified in PBL methodology were in accordance with many of the suggestions of the reforming policies of the GMC. This concordance with educational theory may explain why PBL has been adopted so readily in many medical schools rather than for any evidence-based pedagogical advantages.

It is recognised that the purpose of medicine is to train competent doctors with both good clinical skills and other key skills. However, reduced public funding in higher education may mean that PBL is seen as a means of teaching a larger group of students, using less face-to-face contact. The modern and different approach of PBL may be attractive to institutions trying to seek favour with the GMC. Finally, PBL passes the responsibility of learning to the student.

Much has been written on PBL in the particular context of learning medicine and anatomy. Overall, in the context of basic science teaching, non-PBL courses seem to be slightly favoured although PBL courses seem to produce more confident, practically-minded doctors [72-75]. The PBL enthusiasts claim that if there is little difference in scientific knowledge and improvements in other areas, then it justifies the methodology. However, many of these studies are conducted in centers where PBL has been introduced with enthusiastic proponents with now well-established, PBLbased courses. It is equally difficult to establish a justification for including dissection in an anatomy course and conclusive evidence is unlikely to be found.

It is unlikely that any future study will prove conclusively the supremacy of one teaching method over another. PBL can be delivered in a useful and constructive way or can be an excuse for low teaching levels and disorganised education. Similarly, dissection can provide an opportunity for selfdirected learning and 3-D awareness of anatomy or can be an expensive, undirected practical class.

In response to a government report, which recommended a substantial increase in the number of medical students in the United Kingdom by 2005, several new medical schools have been set up throughout the country. One such school, the Brighton and Sussex Medical School (BSMS), recently opened its doors to new students. BSMS offers a 5-year medical curriculum that uses an integrated systems-based approach to cultivate academic knowledge and clinical experience. Anatomy is one of the core elements of the program and, as such, features strongly within the modular curriculum. The challenge for the anatomy faculty has been to decide how best to integrate anatomy into the new curriculum and what teaching modalities should be used. A multidisciplinary approach has been taken using both traditional and contemporary teaching methods. Unlike most of the other new medical schools, BSMS uses cadaveric dissection as the cornerstone of its teaching, as the faculty believes that dissection still provides the most powerful technique for demonstrating anatomy as well as enhancing communication and teamwork skills. The dissection experience is handled using an understanding and professional way. However, to ensure that our students do not become detached from the process of patient-focused care, emphasis in the dissecting room environment is also placed on respect and compassion. To enhance conceptual understanding of structure and function and provide further clinical relevance, we are using imaging technology to demonstrate living anatomy. Unique to the BSMS curriculum is the teaching of the anatomy in the later years of the program. During specialist rotations, students will return to the dissecting room to study the anatomy relevant to that area. Such vertical integration ensures that core anatomical knowledge is gained at the most appropriate level relative to a student's clinical experience [23].

The practice of dissection, as part of undergraduate medical education, has recently resurfaced in the public eye. Lempp, (2005) [67] has focused on a number of important learning outcomes that were reported by Year 1-5 medical students in a British medical school, during the dissection sessions in the first 2 years of their training, as part of a wider qualitative research project into undergraduate medical education. A group of 29 students was selected by quota sampling, using the whole student population of the medical school as the sampling frame. Qualitative data were collected by $1: 1$ interviews with students and from formal nonparticipatory observations of dissection sessions. Apart from learning to cope with the overt 'emotional confrontation' with the cadavers which assists anatomical learning, 7 additional covert learning outcomes were identified by the students: teamwork, respect for the body, familiarisation of the body, application of practical skills, integration of theory and practice, preparation for clinical work, and appreciation of the status of dissection within the history of medicine. A number of medical schools have either removed the practical, hands-on aspect of dissection in the medical undergraduate curriculum or are seriously considering such a measure, on financial and/or human resource grounds. This study highlights the fact that dissection can impart anatomical knowledge as well as offer other relevant, positive learning opportunities to enhance the skills and attitudes of future doctors [67].

Discussions about dissection as a teaching method in gross anatomy are characterized by a lack of objective evidence. A search for such evidence in the literature produced 14 relevant papers. These were reviewed for objective data on the effect of cadaver dissection on cognitive learning outcomes by Winkelmann, (2007) [76]. All reviewed studies compared groups of students exposed to different teaching approaches, including active dissection, learning on prosected material, or a combination with computerized teaching aids. Study and course designs varied substantially and student groups compared were not always homogeneous. In all studies, compared learning experiences differed in 
more than 1 variable, and assessment of anatomical knowledge was not standardized. It is difficult to interpret and generalize from the results of the reviewed studies. Considering the bias that must be assumed for teachers who develop new course designs and compare these with traditional ones, the review shows a slight advantage for traditional dissection over prosection. He concluded that more sophisticated research designs may be necessary to solve the general problem of the small measurable impact of educational interventions and to come to scientifically sound conclusions about the best way to teach gross anatomy. Such research will have to include sufficient sample sizes, the use of validated assessment instruments, and a discussion of the educational significance of measured differences. More educational research in anatomy is necessary to counterbalance emotional arguments about dissection with scientific evidence. Anatomical knowledge is too important to future doctors to leave its teaching to the educational fashion of the day [76].

\subsection{Trials to Improve the Anatomy Situation in the Medical Curriculum}

Before reorganizing or modernizing an anatomy curriculum or shape a new one within time limits set by the modern curriculum, perhaps the most important question should be that of the most optimal distribution of the "anatomical body of knowledge." An important step in answering this question is to work out how the shape and size of the human body correlates with the shape and size of the modern anatomy curriculum. Most publications concerning gross anatomy deal with issues of teaching methodology - from the instructional design principles in "anatomy of learning" [77] to relationships between learning outcomes and methods of anatomy teaching [78] or the assessment of different educational tools in learning anatomy in a problem-based learning curriculum [59]. Particularly interesting are publications concerning the value of anatomical dissection as a teaching method in medical education, reviewed in a recent article by Winkelman, (2007) [76]. Models for innovative, integrated, and clinically oriented approaches to anatomy education have been proposed $[79,80]$ attitudes of anatomy teachers toward changes of curriculum have been assessed [16,78], and quantity/structure of contact hours (lectures, tutorials, dissections) were compared between medical schools in the United States and Europe [81]. Despite obvious ongoing interest in anatomy education in medical courses, to our knowledge, there is no practical guide about the content of anatomy curriculum and relative sizes of its parts in the literature. Recognizing this problem, Latman and Lanier, (2001) [82] published recommendations (based on opinions of practicing clinicians) for gross anatomy course content for 3 allied health courses (occupational health, physician assistant, and physical therapy) They summarized their results for both regional- and system-based gross anatomy curricula by proposing different percentages of content for each of the three courses. To the best of our knowledge, there is no similar reference for medical or dental courses.

If old-style anatomy teaching is dead, anatomy needs to reinvent itself as a subject. It should evolve to address the requirements of any subject in a medical curriculum in the 21 st century. Some progress has been made. There has been a move from passive, didactic, highly detailed courses towards functionally and clinically relevant courses irrespective of the method of teaching.

For further progress to be made, the traditionalists have to concede that learning large quantities of detailed anatomy is unnecessary for the majority of medical careers, whilst a core of knowledge must be covered and assimilated by all students. Some progress has been made in defining core knowledge [66]. If a core of knowledge is agreed, then its assimilation must be assessed rigorously not only in the first year of medical school but with on-going assessments throughout clinical school and beyond. Acceptance of the concept of core knowledge also requires recognition that this will be inadequate for specialist training. Students entering medical careers which require a more detailed knowledge of anatomy will need access to specialised anatomy training at later stages in their careers. A sustainable solution is for anatomy departments to forge educational and financial links with hospital departments and some medical schools are exploring this option [37]. This would allow vertical integration of anatomy into the medical school curriculum from the first year of medical school, through clinical school and into specialist training, reinforcing the core anatomy by appreciation of its clinical relevance. Involvement of clinical specialists would give them the opportunity to shape the anatomy syllabus according to good clinical practice and advancing techniques, maintain their own knowledge (making them safer practitioners), and help to address the staff shortages in anatomy teaching. The criticisms of specialists about their juniors' lack of anatomical knowledge would be addressed directly and it should produce safer, more competent practitioners, less likely to make mistakes and incur litigation in the future.

How then should students and trainees learn anatomy? First, modernisation should draw on the fact that human anatomy has an innate fascination, not only with medical students and doctors, but with most other healthcare workers and a significant proportion of the general public. Anatomy must shake off the image of being old-fashioned and welcome clinical relevance, the IT revolution, models, body painting, and radiographic images. Anything that stimulates interest in anatomy should be promoted. This, however, does not exclude prosection and dissection as a learning resource and nor does it mean anatomy teaching without appropriate staffing and other resources. The value of new resources such as computer-assisted learning have to be assessed in terms of how much they contribute to the assimilation of core knowledge and student understanding and not in terms of how cost effective or politically appropriate they are [15].

The challenge should not be to determine supremacy of one methodology over another but to maximise the learning benefit available from the different methods. The purpose of 
PBL is to develop reasoning skills, enable learning within a relevant context, encourage work-related skills, and promote self-directed learning. Appropriate use of dissection and prosections can meet many of these aims and have additional benefits. The dissection room should not be abandoned when the evidence is that students and trainees who have minimal exposure to dissections often demand dissection/prosection based teaching at a later date. It must be established what is core knowledge (at the various stages of medical education) so that standards are not allowed to inexorably decline as more cost-effective solutions are explored [15].

Some illustrations showing that the curriculum is a dynamic process with the ways to improve (Figures 1, 2, 3, 4, and 5).

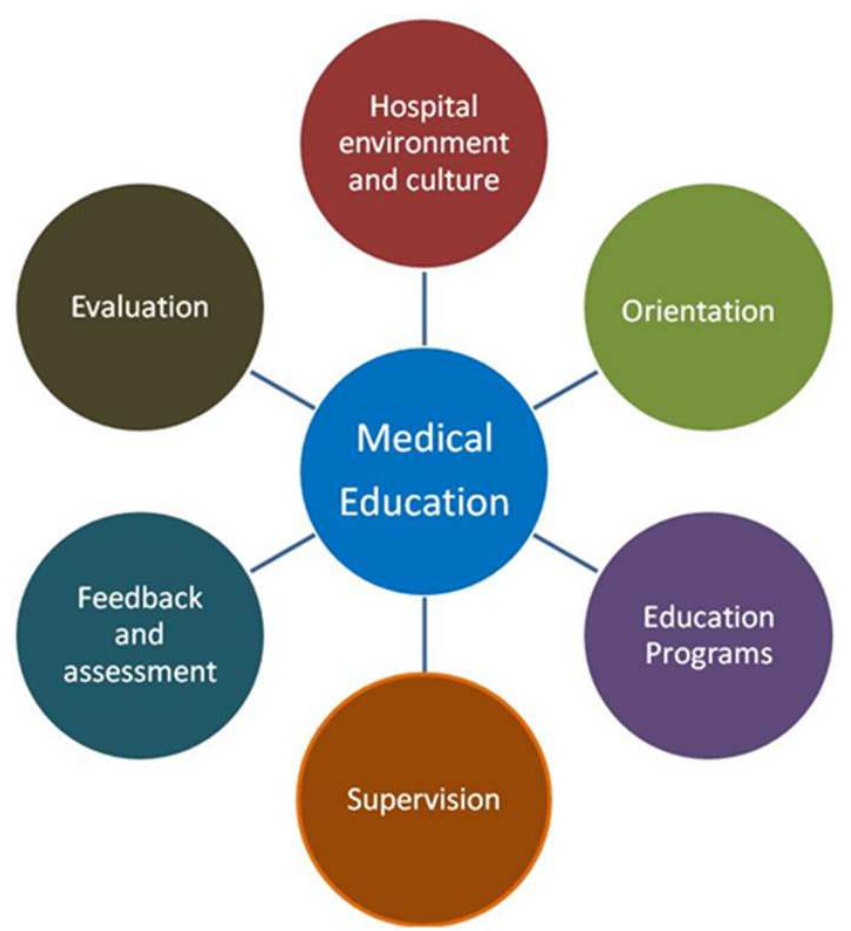

Figure 1. Showing the factors which affect the medical education. [83]

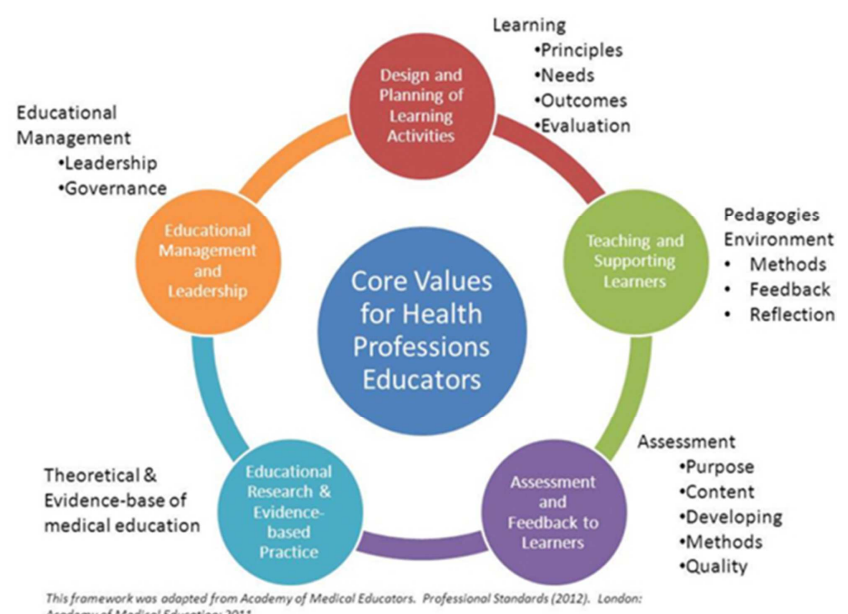

Figure 2. Showing the core values for health professions education. [84]

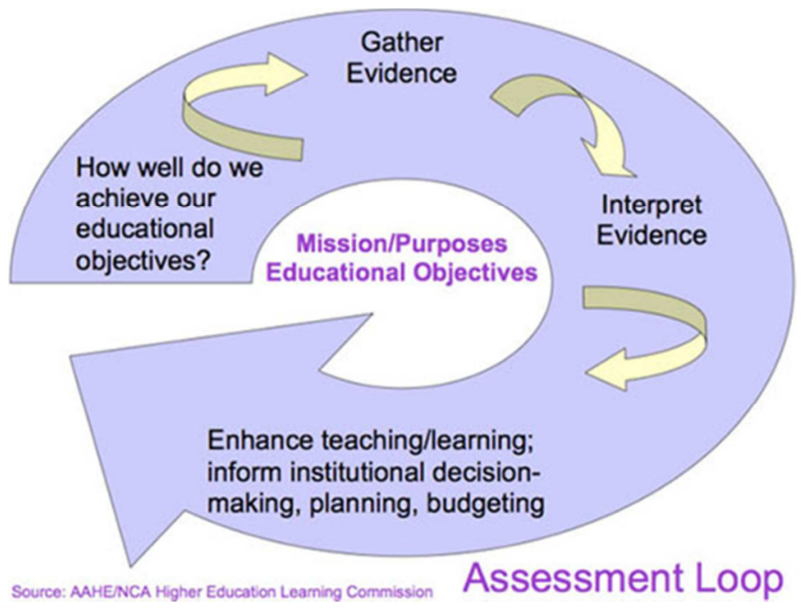

Figure 3. Showing the assessment loop for improving the curriculum. [85]

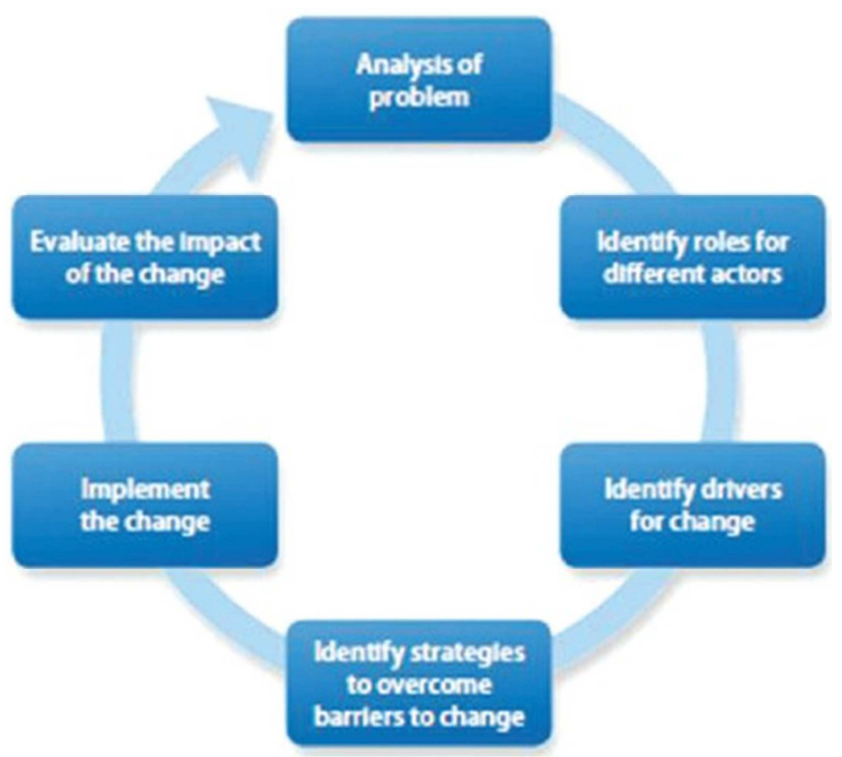

Figure 4. Showing the policy cycle to improve the curriculum. [86]

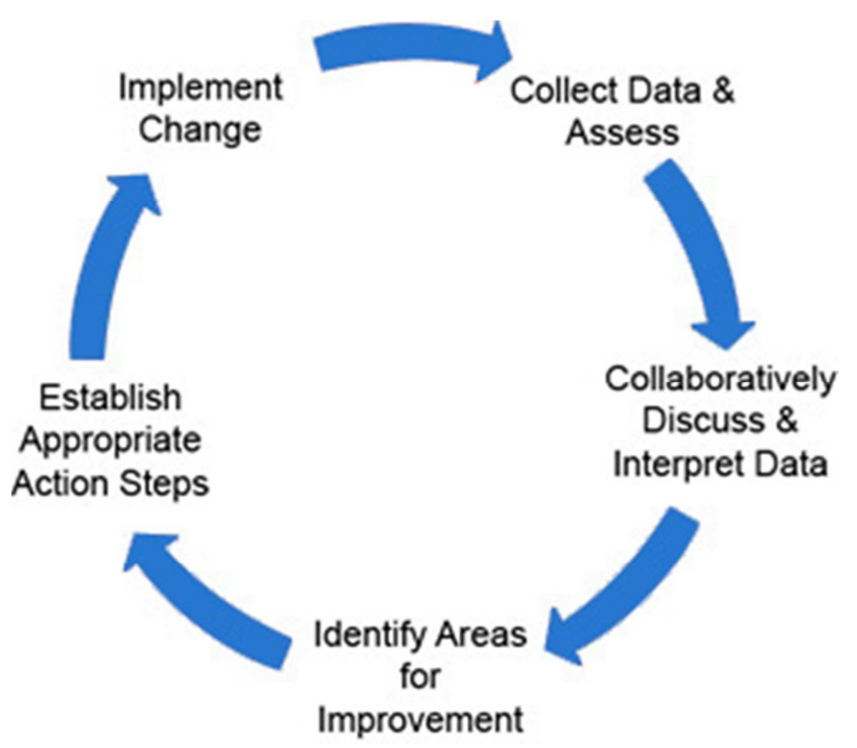

Figure 5. Showing the key stages to an evidenced-based approach to collaborative curriculum decision-making. [87] 


\section{Conclusions}

Some of the medical schools teach anatomy as part of the modules in the first two years, whereas in some institutions, core courses of anatomy are offered in the first year and system based anatomy is covered in the second year, In some medical schools with traditional curriculum the anatomy is taught as core courses in the first two years, whereas in some other institutions with a Problem Based Learning (PBL) curriculum the anatomy is taught as a part of the PBL system. The core knowledge and the Anatomy learning objectives should be the same, whatever teaching approaches are adopted within a curriculum.

The challenge should not be to determine supremacy of one methodology over another but to maximize the learning benefit available from the different methods.

For further progress in teaching anatomy to be made, the traditional anatomists have to concede that learning large quantities of detailed anatomy is unnecessary for the majority of medical careers, whilst a core of knowledge must be covered and assimilated by all students.

It must be established what is core knowledge (at the various stages of medical education) so that standards are not allowed to inexorably decline as more cost-effective solutions are explored.

Leading anatomists have to put together some guidelines on an anatomy curriculum which they feel any medical practitioner should know.

There is a need to move from passive, didactic, highly detailed courses towards functionally and clinically relevant courses irrespective of the method of teaching.

A sustainable solution is for anatomy departments to forge educational and financial links with the hospital departments. This would allow vertical integration of anatomy into the medical school curriculum from the first year of medical school, through clinical school and into specialist training, reinforcing the core anatomy by appreciation of its clinical relevance.

In any model of medical curricula, a professional team of medical anatomists have to share in all the steps of curriculum building, the assessment tools and the final evaluation till the approval of the curriculum to:

1. Ensure that all the basic anatomical objectives are chronologically arranged and sufficiently covered in a suitable time and methodology without inflation of the curriculum by more sophisticated details which taught only for the postgraduate students and medical anatomists.

2. Prevent any restriction of important basic knowledge which will not be covered later on and will affect the physician medical practice.

3. Ensure that all the basic anatomical objectives are demonstrated with their clinical application without the sophisticated details of the clinical points which will be taught in details in the clinical years.

\section{References}

[1] Tyler, R. W. (1949): Basic Principles of Curriculum and Instruction. Chicago, IL: University of Chicago Press.

[2] Taba, H. (1962): Curriculum development theory and practice. New York, NY: Harcourt Brace \& World.

[3] Ontario Association for Curriculum Development (1983): The Colonel Watson Award (certificate).

[4] Wilson, L. O. (1990, 2004, 2006): Curriculum course packets ED 721 \& 726, unpublished.

[5] J. G. Donald, "Knowledge and the University Curriculum," Higher Education 15 (Nos. 3-4 1986): 267.

[6] Geofferey Squires, First Degree: The Undergraduate Curriculum (Buckingham, England: Society for Research into Higher Education, 1990), ERIC document ED 326168.

[7] Arthur Levine, Handbook on Undergraduate Curriculum (San Francisco: Jossey-Bass, 1981).

[8] Harold Taylor, ed., Essays in Teaching (New York: Harper, 1950), p. 220.

[9] Laurence Veysey, "Stability and Experiment," in Content and Context, ed. Carl Kaysen (New York: McGraw-Hill, 1973), p. 73.

[10] Joan S. Stark and M. A. Lowther, Designing the Learning Plan: A Review of Research and Theory Related to College Curriculum (Ann Arbor: Regents of the University of Michigan, 1986), p. 45.

[11] Thomas S. Popkewitz, "Knowledge, Power: A General Curriculum," in Cultural Literacy and the Idea of General Education, 87th Yearbook of the National Society for the Study of Education, part 2, ed. Ian Westbury and Alan C. Purves (Chicago: University of Chicago Press, 1988), p. 69.

[12] William E. Toombs and William G. Tierney: Curriculum Definitions and Reference Points; Journal of curriculum and supervision. Spring 1993 | Volume 8 | Number 3 Pages 175195.

[13] McGaghie WC, Miller GE, Sajid AW and Telder TV. Competency based curriculum development in medical education - An introduction: World Health Organization Geneva 1978 .

[14] J.E.F. Fitzgerald, M.J. White, S.W. Tang, C.A. MaxwellArmstrong, And D.K. James: Are We Teaching Sufficient Anatomy at Medical School? The Opinions of Newly Qualified Doctors: Clinical Anatomy 21:718-724 (2008).

[15] Turney BW. Anatomy in a modern medical curriculum. Ann R Coll Surg Engl 2007; Mar. 89(2): 104-107.

[16] Patel KM, Moxham BJ. 2006. Attitudes of professional an atomists tocurricular change. Clin Anat 19:132-141.

[17] Older J.: Anatomy: a must for teaching the next generation. Surgeon. 2004 Apr;2(2):79-90.

[18] Raftery AT. 2006. Anatomy teaching in the UK. Surgery 25:1-2.

[19] McLachlan JC. 2004. New path for teaching anatomy: living anatomy and medical imaging vs. dissection. Anat Rec B New Anat 281:4-5. 
[20] Department of Health. 2003. Modernising Medical Careers. The Response of Four UK Health Ministers to the Consultation on Unfinished Business: Proposals for Reform of the Senior House Officer Grade. London: Department of Health.

[21] Holla SJ, Selvaraj KG, Isaac B, Chandi G. 1999. Significance of the role of self-study and group discussion. Clin Anat 12:277-280.

[22] Dangerfield P, Bradley P, Gibbs T. 2000. Learning gross anatomy in a clinical skills course. Clin Anat 13:444-447.

[23] Evans DJ1, Watt DJ.: Provision of anatomical teaching in a new British medical school: getting the right mix. Anat Rec B New Anat. 2005 May; 284(1):22-7.

[24] Heylings DJ: Anatomy 1999-2000: the curriculum, who teaches it and how? Med Educ. 2002 Aug; 36(8):702-10.

[25] Leong SK. 1999. Back to basics. Clin Anat 12:422-426.

[26] Robotham J. Anatomy of a dissection debate. Sydney Morning Herald. [Published 14 April 2011, cited 3 August 2013.] Available from URL: http://www.smh.com.au/world/science/anatomy-of-adissection-debate-20110413-1deaf.html.

[27] Smith JA. Can anatomy teaching make a comeback [editorial]? ANZ J Surg 2005; 75: 93.

[28] Linacre J. Whither anatomy teaching?: A student perspective [editorial]. ANZ J Surg 2005; 75: 96-97.

[29] Hanwell S, Davies DC, Morris J, et al. A core syllabus in anatomy for medical students - adding common sense to need to know. Eur J Anat 2007; 11(Supplement 1):3-18.

[30] Ramsey-Stewart G, Burgess AW, Hill DA. Back to the future: teaching anatomy by whole-body dissection. Med J Aust 2010 (11/12): 668-671.

[31] Ramsden P. Learning to Teach in Higher Education. 2nd edn. London: Routledge Falmer; 2003. Approaches to learning (Chapter 4) pp. 39-61. ISBN 0-415-30345-1.

[32] Ramsden P. Learning to Teach in Higher Education. 2nd edn. London: Routledge Falmer; 2003. Learning from the student's perspective (Chapter 5) (ISBN 0-415-30345-1).

[33] McHanwell S, Atkinson M, Davies D C, Dyball R, Morris J, Ockleford C. A core syllabus in anatomy for medical students - Adding common sense to need to know: Eur J Anat, 11 (Supplement 1) 2007: 3-18.

[34] European University Association. Activities. Bologna Process. Joint Declaration of the European Ministers of Education convened in Bologna on 19 June 1999. Available at: http://www.eua.be/bologna- universities-reform/bolognabasics/. Accessed: December 29, 2008.

[35] McKeown PP, Heylings DJ, Stevenson M, McKelvey KJ, Nixon JR, McCluskey DR. The impact of curricular change on medical students' knowledge of anatomy. Med Educ. 2003;37:954-61.

[36] Kaufman MH. Anatomy training for surgeons - a personal viewpoint. J R Coll Surg Edinb. 1997;42:215-6.

[37] Shaffer K. Teaching anatomy in the digital world. N Engl J Med. 2004;351:1279-82.
[38] Anon. The rise and fall of anatomy. BMJ Career Focus. 2005;330:255-6.

[39] Waterston SW, Stewart IJ. Survey of clinicians' attitudes to the anatomical teaching and knowledge of medical students. Clin Anat. 2005;18:380-4.

[40] Prince KJ, Scherpbier AJ, van Mameren H, Drukker J, van der Vleuten CP. Do students have sufficient knowledge of clinical anatomy? Med Educ. 2005;39:326-32.

[41] P. Groscurth, P. Eggli, J. Kapfhammer, G. Rager, J.-P. Hornung, And J.D.H. Fasel: Gross Anatomy in the Surgical Curriculum in Switzerland: Improved Cadaver Preservation, Anatomical Models, and Course Development; THE Anatomical Record (New Anat.) 265:254-256, 2001.

[42] Julius ogeng'o, Kevin Ongeti, Musa Misiani, Beda Olabu.: Maintaining Excellence In Teaching Of Human Anatomy: University Of Nairobi Experience; Anatomy Journal of Africa 2 (1): 117-129(2013).

[43] Aziz MA, Mc Kenzie JC, Wilson JS, Cowie RJ, Ayeni SA, Dunn BK. 2002. The human cadaver in the age of biomedical informatics. Anat Rec 269: 20-32.

[44] Vazquez R, Rusco JM, Carretero J. 2005. Reflections and challenges in teaching of human anatomy at the beginning of the 21st century. Eur J Anat 9: 111-115.

[45] Ellis H. 2001. Teaching in the dissection room. Clin Anat 14: 149-151.

[46] Rizollo LJ, Stewart WB. 2006. Should we countinue teaching anatomy by dissection when----? Anat Rec B New Anat 189B: $215-218$.

[47] Satyapal KS, Henneberg M. 1997. Anatomy into the next millennium: Quo vadis, or simply where to? Clin Anat 10: 4143.

[48] Cahill DR, Leonard RJ, Marks Jr SC. 2000. A comment on recent teaching of human anatomy in the United States. Surg Radiol Anat 22: 69-71.

[49] Tavares MAF, Viera AJ, Trigueiros CN, Dinis MJ, Cardoso V, Sikva MC. 2002. Evaluation of practical sessions in clinical anatomy: A strategy for educational improvement. Clin Anat 15: $51-55$.

[50] Boon JM, Meiring JH, Richards PA, Jacobs CJ. 2001. Evaluation of clinical relevance of problem oriented teaching in undergraduate anatomy at the University of Pretoria. Surg Radiol Anat. 23:57-60.

[51] Ongeti K. 2012. Pedagogical Value of Dissection Anatomy in Kenya. Singapore med J 53: 712 - 714.

[52] Gangata H, Ntaba P, Akol P. Louw G. 2010. The reliance on unclaimed cadavers for anatomical teaching by medical students in Africa. Anat Sci Edu 3: 174 - 183.

[53] Bekele A, Reissig D, Loffler S, Hinz A. 2011. Experiences with dissection courses in human anatomy: a comparison between Germany and Ethiopia. Ann Anat 193: 163 - 167.

[54] Ogunranti JO. 2008. Challenges and prospects of anatomy in the 21 st century. 6th scientific conference - anatomical society of Nigeria, Ahmadu Bello University Zaria - 16th October. 
[55] Rizzolo LJ.: Human dissection: an approach to interweaving the traditional and humanistic goals of medical education. Anat Rec. 2002 Dec 15;269(6):242-8.

[56] Cottam WW. 1999. Adequacy of medical school gross anatomy education as perceived by certain postgraduate residency programs and anatomy course directors. Clin Anat $12: 55-65$.

[57] Drake RL, Lowrie DJ Jr, Prewitt CM. 2002. Survey of gross anatomy, microscopic anatomy, neuroscience, and embryology courses in medical school curricula in the United States. Anat Rec 269:118-122.

[58] Plaisant O, Cabanis EA, Delmas V. 2004. Going back to dissection in a medical curriculum: The paradigm of NeckerEnfants Malades. Surg Radiol Anat 26:504-511.

[59] Azer SA, Eizenberg N. 2007. Do we need dissection in an integrated problem-based learning medical course? Perceptions of firstand second-year students. Surg Radiol Anat 29:173-180.

[60] Prince KJ, Scherpbier AJ, Van Mameren H, Drukker J, van der Vleuten CP. 2005. Do students have sufficient knowledge of clinical anatomy? Med Educ 39:326-332.

[61] Spielmann PM, Oliver CW. 2005. The carpal bones: a basic test of medical students' and junior doctors' knowledge of anatomy. Surgeon 3:257-259.

[62] Ellis H. Medico-legal litigation and its links with surgical anatomy. Surgery. 2002;20:i-ii.

[63] Turney BW, Gill J, Morris JF. Surgical trainees as anatomy demonstrators: revisited. Ann R Coll Surg Engl (Suppl) 2001;83:193-5.

[64] Schmidt HG, Dauphinee WD, Patel VL.: Comparing the effects of problem-based and conventional curricula in an international sample. J Med Educ. 1987 Apr;62(4):305-15.

[65] Dyball R. members of the Education Committee of the Anatomical Society and others. Setting a benchmark for anatomical knowledge and its assessment (A core curriculum for the teaching of anatomy to medical students) 2003. < http://www.anatsoc.org.uk/linkfiles/anat-core-curric.htm>.

[66] Snelling J, Sahai A, Ellis H. Attitudes of medical and dental students to dissection. Clin Anat.2003;16:165-72.

[67] Lempp HK1.: Perceptions of dissection by students in one medical school: beyond learning about anatomy. A qualitative study. Med Educ. 2005 Mar;39(3):318-25.

[68] Dinsmore CE, Daugherty S, Zeitz HJ. Teaching and learning gross anatomy: dissection, prosection, or 'both of the above'? Clin Anat. 1999;12:110-4.

[69] Jones DG. Reassessing the importance of dissection: a critique and elaboration. Clin Anat. 1997;10:123-7.

[70] Cahill DR, Leonard RJ. The role of computers and dissection in teaching anatomy: a comment [editorial]Clin Anat. 1997;10:140-1.

[71] Barrows HS, Tamblyn RM. Problem-Based Learning: An Approach to Medical Education. New York: Springer; 1980.
[72] Schmidt HG, Dauphinee WD, Patel VL. Comparing the effects of problem-based and conventional curricula in an international sample. J Med Educ. 1987;62:305-15.

[73] Albanese MA, Mitchell S. Problem-based learning: a review of literature on its outcomes and implementation issues. Acad Med. 1993;68:52-81.

[74] Vernon DT, Blake RL. Does problem-based learning work? A meta-analysis of evaluative research.Acad Med. 1993;68:550 63.

[75] Verhoeven BH, Verwijnen GM, Scherpbier AJJA, Holdrinet RSG, Oeseburg B, Bulte JA, et al. An analysis of progress test results of PBL and non-PBL students. Med Teacher. 1998;20:310-6.

[76] Winkelmann A.: Anatomical dissection as a teaching method in medical school: a review of the evidence. Med Educ. 2007 Jan;41(1):15-22.

[77] Terrell M. Anatomy of learning: instructional design principles for the anatomical sciences. Anat Rec B New Anat. 2006;289:252-60.

[78] Patel KM, Moxham BJ. The relationships between learning outcomes and methods of teaching anatomy as perceived by professional anatomists. Clin Anat. 2008;21:182-9.

[79] Evans DJ, Watt DJ. Provision of anatomical teaching in a new British medical school: getting the right mix. Anat Rec B New Anat. 2005;284:22-7.

[80] Drake RL. A unique, innovative, and clinically oriented approach to anatomy education. Acad Med. 2007;82:475-8.

[81] Plaisant O, Cabanis EA, Delmas V. Going back to dissection in a medical curriculum: the paradigm of Necker-Enfants Malades Surg Radiol Anat. 2004;26:504-11.

[82] Latman NS, Lanier R. Gross anatomy course content and teaching methodology in allied health: clinicians' experiences and recommendations. Clin Anat. 2001;14:152-7.

[83] Medical Education Unit, Education Precinct, Ground Floor West, Main Building The Royal Melbourne Hospital, Grattan Street, Parkville 3050, Victoria Australia, http://www.mh.org.au/royal melbourne hospital/medicaleducation-unit/w1/i1001222/.

[84] The Pioneer Fellows Program, a 12-month structured training program for clinician educators kicked off on 23 February 2013 with an Orientation session. https://www.singhealth.com.sg/Education/News/Pages/AMEIPioneer-Fellows-embark-on-teaching-excellencejourney.aspx.

[85] http://condor.depaul.edu/tla/Assessment/AssessmentMethodol ogy.html 2001-2012 DePaul University 1 E. Jackson, Chicago, IL 60604 | 312-362-8000.

[86] Shah C, Parmar D, Mehta H. Perceptions of faculty about student-centered curriculum. Arch Med Health Sci 2014;2:749.

[87] Banta, T. W. and Blaich, C. (2011) Closing the Assessment Loop. Change: The Magazine of Higher Learning 43: 1, 22-27. 